\title{
Caribbean Landscape and Visual Imagination: An analysis of Derek Walcott's Poems by Barbara $D$. Constance
}

\author{
Dr. Barbara D. Constance
}

The University of Trinidad and Tobago, Trinidad and Tobago

\author{
Though our longest sun sets at right declensions and makes but winter arches, it cannot be long \\ before we lie down in darkness, and have our light in ashes... \\ - BROWNE, Urn Burial
}

Derek Walcott's work lends itself to the analysis and evaluation of a plethora of themes and perspectives. This paper seeks to analyze and evaluate the notion of visual imagination in the poetic works of this renowned scholar. The paper looks specifically at three poems in his work, Collected Poems 1948-1984. The poems include 'Egypt Tobago', 'Ruins of a Great House' and 'Jean Rhys'. This paper takes into consideration the extent to which Derek Walcott appeals to and stimulates the visual imagination. This presentation seeks to highlight how Derek Walcott uses the pen to portray images that are peculiar to and inherent in the Caribbean landscape and culture and the dynamic creativity he uses to achieve this.

The work also takes a look at what critics would have said on the issue of themes that relate to visual imagination. These works will be evaluated with a view to critiquing the extent of their reality, relevance and application in the context of the Caribbean's landscape and soul. They will also be analyzed with reference to the poems that have been chosen for this presentation.

The paper will be examined from a critical discourse analysis approach, where patterns and variations that stem from these patterns will be looked for. These patterns can stem from different levels including lexical, grammatical and semantic levels. These levels will be used as the categories within which the idea of visual imagination will be evaluated. Also included is the relationship between language and power, which, according to Weiss and Wodak (2002: 12), "considers more or less overt relations of struggle and power".

One of the delights afforded us through the works of Derek Walcott is his determination to make us see visualize. His own ability to articulate his visual imagination from the tangible world captures our imagination and encourages us to picture more vividly what we may have overlooked in the quest of living or what we may have chosen to forget as individuals, as a nation, as a people. His visual representations are constructed using the known so that the reader is without excuse; he/she cannot say that there is nothing in the poem to relate to. Thus, the seen, the tangible is brought to the page, allowing us to connect with the unseen within the boundless imagination, which if tapped into can generate numerous connections, discoveries and thus solutions, where necess ary. The notion of visual imagination, therefore, takes us into a world, that, if carefully considered and manipulated, holds the key to the survival of the landscape and life around us.

Walcott's work connects to the visual imagination through his use of colour, shapes, textures, movement and events. Thus, he uses what connects to our visual sensory organ, the eye, which connects to the brain. However, he skillfully uses language to paint images that can be as sociated with literal images, which can be associated with memories stored in the brain, which would themselves have entered through the portal of the eye, recipient of visual tangibles.

Walcott's poetry, with its rich use of visual imagery connects with our own memories, fuelling imagination that leaves our thinking changed to some degree. The whole notion of visual imagination can be studied in his poems 'Jean Rhys', 'Ruins of a Great House' and Egypt, Tobago'. These three were chosen as they present the diversity of Walcott's ability to manipulate visual images using a variety of entities, including humanity, the dwellings place and landscape. However, none of these poems is constricted to one entity. Each contains visual representations of a combination of entities that prod and provoke the imagination to realization, to action, to decision and to life. 
'Ruins of a Great House', first presents an extract from Browne that itself presents visuals that are undeniable. This extract as it were prepares the reader for a major theme in the poem, the theme of decay. Hence, before we read of the ruins of a house, great as it may be, we are reminded of our own inevitable, lifelong decay, which inches upon us from our birth. Thus the extract speaks of the inevitability of death as represented by darkness. This 'darkness' representing death is a symbol that can be appreciated worldwide as a time of despair, quiet, sleep and inactivity. In physics in the field of optics, we learn that light is needed for us to see, to visualize. Thus, the visualization takes place while are yet in the zone of light.

The extract represents our lives as the sun; the ultimate representation of physical light, which if representing the day soon gives way to darkness and if representing the heat of summer, gives way to autumn and then to winter, which he uses to represent the final end of man, who after years of activity remain frozen in one spot, death. Thus, we expect to encounter in 'Ruins of a Great House' the fall of the mighty, the once illustrious, the once prominent. Even before we read the poem itself we are prepared for what is really the lot of all, the one moment at least when all, to all appearances is lost. That 'all' reaches to even monuments, empires, and cities.

In the poem, the reader is greeted by the phrase, '[s]tones only', as concrete and widely known concrete image as one can encounter. The image conjures up ideas of the lack of usefulness, importance and life. There are no illusions of any prospect of this place serving any purpose to the living anymore. As one pictures the image of stones, we think of the bare materials that would have been the raw materials for a once illustrious place that has reverted to bare materials. It reminds the reader of somber words, 'ashes to ashes' 'dust to dust.' The coupling of these two words (stones only) as a phrase gives an idea of brevity and abruptness. Thus when we get to the actual term 'great house', we are not tempted to think that there is possibilities of life. Other visual signs of uselessness and dejection are words such as 'candledust', stain', 'muck' and 'cattle droppings'. All of these images are presented in the first stanza of the poem as testaments to the absence of life. They speak of lack of care and attention to this once grandiose structure. The reader cannot help but imagine a place that has not been tended for in ages. This is compounded by the realization that this place was not an ordinary dwelling place.

This realization comes about through the description of the structures in the midst of the painting of the mess that is left. In the rubble left behind, we read of the 'gate cherubs', 'marble' and 'grille ironwork'. These descriptions are not fully developing or fronted as information giving the reader the sense that they are just a shadow of what they use to be. They no longer hold any prominence or importance. However, they serve to highlight the contrasts between what was past and what is present. In the brief appearance the reader can have piece together an image of how splendid this place once was.

The 'Great House' seems to cry out in protest and almost pain to any who would venture on its property to observe. The expression, ' $[t]$ he mouths of those gate cherubs shriek with stains' speaks of the helplessness of the situation. The 'gate cherubs' are inert objects without the power to restore what has been abandoned, destroyed. These seem to stand as guardians of this rejected property, trying to tell anyone entering who would give an ear, of the disregard of the property. To compound the warning of these inanimate fixtures, Walcott introduces moving, kinetic imagery in the use of the 'three crows' that 'flap for trees and settle'. Thus, the mind is moved to build on the image of death and abandonment. One can imagine moving through the property and shifting one's attention from the frozen and still images of death as movement captures the attention for a while. However, the movement is made by the birds that are as sociated with death.

Walcott does not slacken his assault on our senses, as he shifts immediately from appealing to sight and movement, to appealing to the sense of smell. He ensures that, if not through all, one would be appealed to through some channel. The 'smell of dead limes quickens in the nose' gives the idea of inhalation and the circulation of this scent through the body. Thus, at this point the reader cannot but take notice of the extent of the physical decay presented. It fills up the senses and causes the reader to pay more rapt attention.

Therefore, the spoken words seem appropriate at this point. The reader's mind can better receive and assimilate the words, "Farewell, green fields, / Farewell, ye happy groves!" (Milton's Paradise Lost) The contrast of what is voiced in these two sentences is more pronounced. After having walked through, and encountered, the evidences of death, decay and neglect, one is almost surprised to learn that this property was once alive, happy and green. We hear the pathos in the words, the pull of heartstring $s$ in the speaker for what once was, for a time when things were right, for a glorious past. That past is briefly described giving the reader enough to capture and reconstruct mentally the extent of the grandeur that once existed. One reads of 'Marble like Greece, like Faulkner's South'. However, that quickly gives way to the present as we are reminded, as in the beginning that now 
there remain stones. What once was is gone as with the 'deciduous beauty' which 'prospered'.

Any remaining doubts as to the pers ona's views are disbanded as we encounter the use of the first person subject. We read, 'I climbed a wall', 'I heard what Kipling heard'. This use of ' $\mathrm{I}$ ' draws the reader even further in to the poem. The reader is not just constructing ideas and visions of what is and what was. The reader is joined by another presence, that of the persona. The reader's attention turns to him because he is the one who has been feeding the reader with images. He is the one who has been giving the reader the material to make connections between the past and the present. His presence, therefore, undeniably holds the attention of the reader. He can give some insight and the reader is primed to hear.

As the persona talks of the 'worm's rent' and the 'calvary of the mouse', he goes beyond this present, continuous decay to the source of this decay. He says, "And when a wind shook in the limes I heard / What Kipling heard, the death of a great empire, the abuse / Of ignorance by Bible and by sword'. This seems to be as important as having painted the picture of what is and briefly adding a spattering of what was. This is the link, the clue, the reason for this poignant passing away. We seem to stand as part of the chain of those who have received this message and thus, who can pass it on. The representation of this message coming on the wind, adds a mystic quality to the scenario. This is not hearsay. The wind, which has been around forever, is able to bring what Kipling heard to the persona, who passes it on to us. We are not left in ignorance as those who had been destroyed. We, like Kipling, like Walcott, now have the information and thus, the remedy to prevent the death of the present empires.

This 'abuse of ignorance by Bible and sword' attests to the destruction that can come from two items that are vastly different. In fact, there is the sense that even though something may be used to save and protect, the potential to cause destruction is great if this item is abused or used as a symbol or object of abuse. There is also the frightening prospect of the vulnerability of the ignorant to abuse of any kind because they may not recognize it as abuse. This ignorance that leads to annihilation can only be overcome through knowledge. This is where the visual imagination should lead us. It is not enough to picture the grandeur of the past that ended in destruction and why. The visual imagination should go beyond the sights and sounds and reas ons and conjure up solutions to keep our present societies and cultures from destruction through ignorance. That abuse may not be through the use of Bible and sword. It may be through some other insidious devices that, if we are not observant enough, may quietly lead our known civilization to ruins

The visual imagination in Walcott's work could only have been possible through his own visual imagination. He understands the power of 'ancestral murderers and poets'. He is aware of the 'ulcerous crimes' committed through the ages. As such he is calling us to fuel our imagination, to dare to think and own our lands, to dare to believe that we can have a culture of knowledge that can survive. He does merely want us to enjoy poetry as we sit in the shade. He seems to want us to ever be aware that 'Albion too was once a colony like ours,' Shakespeare's Henry $V$.

\section{REFERENCES}

[1] Walcott, Derek. (1990). Collected poems: 1948-1984. London: Faber \& Faber.

[2] Weiss, Gilbert, \& Wodak, Ruth (eds). (2002). Critical discourse analysis: Theory and interdisciplinarity. Vienna: Palgrave Macmillan. 